\title{
Scalable production of biliverdin IXa by Escherichia coli
}

\author{
Dong Chen", Jason D Brown ${ }^{1}$, Yukie Kawasaki², Jerry Bommer ${ }^{3}$ and Jon Y Takemoto ${ }^{1,2 *}$
}

\begin{abstract}
Background: Biliverdin IXa is produced when heme undergoes reductive ring cleavage at the a-methene bridge catalyzed by heme oxygenase. It is subsequently reduced by biliverdin reductase to bilirubin IXa which is a potent endogenous antioxidant. Biliverdin IXa, through interaction with biliverdin reductase, also initiates signaling pathways leading to anti-inflammatory responses and suppression of cellular pro-inflammatory events. The use of biliverdin IX as a cytoprotective therapeutic has been suggested, but its clinical development and use is currently limited by insufficient quantity, uncertain purity, and derivation from mammalian materials. To address these limitations, methods to produce, recover and purify biliverdin IXa from bacterial cultures of Escherichia coli were investigated and developed.
\end{abstract}

Results: Recombinant E. coli strains BL21(HO1) and BL21(mHO1) expressing cyanobacterial heme oxygenase gene hol and a sequence modified version (mho 1) optimized for E. coli expression, respectively, were constructed and shown to produce biliverdin IXa in batch and fed-batch bioreactor cultures. Strain BL21(mHO1) produced roughly twice the amount of biliverdin IXa than did strain BL21(HO1). Lactose either alone or in combination with glycerol supported consistent biliverdin IXa production by strain BL21( $\mathrm{mHO} 1$ ) (up to an average of $23.5 \mathrm{mg} \mathrm{L}^{-1}$ culture) in fed-batch mode and production by strain BL21 (HO1) in batch-mode was scalable to 100 bioreactor culture volumes. Synthesis of the modified hol gene protein product was determined, and identity of the enzyme reaction product as biliverdin IXa was confirmed by spectroscopic and chromatographic analyses and its ability to serve as a substrate for human biliverdin reductase A.

Conclusions: Methods for the scalable production, recovery, and purification of biliverdin IXa by E. coli were developed based on expression of a cyanobacterial hol gene. The purity of the produced biliverdin IXa and its ability to serve as substrate for human biliverdin reductase A suggest its potential as a clinically useful therapeutic.

Keywords: Biliverdin IXa, Heme oxygenase, Escherichia coli, HO1, Bilirubin, Anti-inflammatory, Biliverdin reductase, Bioreactor

\section{Background}

Biliverdin is a linear tetrapyrrole produced by ring cleavage of heme catalyzed by the enzyme heme oxygenase (HO) (E.C.C.1.14.99.3) [1]. In animals, heme cleavage by $\mathrm{HO}$ occurs selectively at the $\alpha$-methene bridge to generate the most physiologically relevant biliverdin IX $\alpha$ isomer. Hence, the term "biliverdin" typically refers specifically to biliverdin IX $\alpha$, and this usage is applied

\footnotetext{
* Correspondence: jon.takemoto@usu.edu

${ }^{1}$ Synthetic Bioproducts Center, 620 North 600 East, Utah State University,

North Logan, Utah 84341, USA

${ }^{2}$ Department of Biology, 5305 Old Main Hill, Utah State University, Logan,

Utah 84322, USA

Full list of author information is available at the end of the article
}

throughout in this paper. Biliverdin is best known as a degradative intermediate associated with erythrocyte and hemoglobin turnover. It is subsequently reduced via NADPH biliverdin reductase (E.C.C. 1.3.1.24) to bilirubin IX $\alpha$ that in turn is consecutively bound to serum albumin and glucuronic acid for excretion in bile. The overall process serves to eliminate heme - which is toxic when accumulated.

Bilirubin IX $\alpha$ is also known to associate with cell membranes where it quenches the propagation of reactive oxygen species (ROS) [2,3] conferring protection to membrane lipids and proteins against oxidative damage. Thus, an additional function of biliverdin is to serve as the immediate source of bilirubin IX $\alpha$ that in turn acts

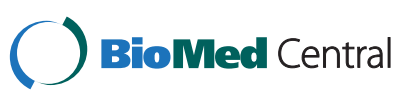


as a cytoprotective antioxidant. It is not clear if biliverdin is oxidatively regenerated after bilirubin IX $\alpha$ reacts with ROS [4-7]. Though bilirubin IX $\alpha$ is an effective ROS quencher, biliverdin administered at tissue injury/ inflammatory sites appears as effective a cytoprotectant as bilirubin IX $\alpha$ [8-13]. Biliverdin's effectiveness has been attributed to its hydrophilicity and efficient conversion to bilirubin IX $\alpha$ [1]. In addition, biliverdin interaction with biliverdin reductase signals the downstream production of anti-inflammatory cytokine interferon-10 [14] and the nitrosylation-dependent inhibition of proinflammatory TLR4 expression [15]. Thus, biliverdin, acting together with biliverdin reductase, is increasingly recognized as a potential anti-inflammatory therapeutic agent [3,16-18]. Examples of its cytoprotective effects in animal models include those for ischemia/reperfusion following liver [19] and small bowel [10] transplants, vascular injury [20], endotoxic shock [21], vascular intimal hyperplasia [9], and nephropathy [8]. In addition, biliverdin has been reported to inhibit in vitro replication of hepatitis $C$ [22] and other viruses [23,24] and to reverse parameters of type 2 diabetes in mice [25]. The growing list of potential clinical applications for biliverdin suggests a future need for high-quality preparations in ample quantity.

Biliverdin is also produced by microbes and plants [26-30]. In cyanobacteria, red algae, and plants, it serves primarily (and perhaps solely) as precursor to photosensitive linear tetrapyrroles such as phycocyanobilin and phycoerythrobilin [31]. These in turn serve as chromophores for cyanobacterial and red algal lightharvesting phycobiliprotein complexes and the lightsensing receptor phytochrome $[27,32]$. In these organisms, biliverdin IX $\alpha$ is the predominant isomer produced via $\mathrm{HO}$ enzymes with sequence homologies to mammalian HO1 [28,33,34].

To meet the projected pharmaceutical demand for biliverdin, high yield and low cost methods that provide the IX $\alpha$ isomer in high purity and preferably from nonmammalian sources are needed. Currently, commercial biliverdin is predominantly derived by chemical oxidation of bilirubin [35]. The source bilirubin (that occurs in conjugated form) is extracted from mammalian bile under acidic conditions that generate isomers (e.g. III $\alpha$ and XIII $\alpha$ isoforms) and consequently lead to biliverdin preparations of unsuitable purity (e.g. as low as $38 \%$ biliverdin IX $\alpha$ [36]). Reported non-mammalian synthesis of biliverdin include Escherichia coli cultures expressing HO1 from rat [37,38] and cyanobacteria [39] and yeast cultures supplemented with hemoglobin [40]. In these reports, the amounts of biliverdin produced are not documented or appear low. Biliverdin extracted from salmon bile is reported [41], but the potential for scalable production is not discussed.
Here, we report the use of $E$. coli to synthesize biliverdin and describe procedures for the scalable production of the IX $\alpha$ isomer. This was achieved by sequence optimization of the cyanobacterial hol gene for enhanced expression in $E$. coli and development of growth culture parameters that promote biliverdin production.

\section{Methods}

\section{E. coli strains and vectors}

One Shot ${ }^{\circledR}$ TOP10 Chemically Competent E. coli (Life Technologies, Carlsbad, CA, USA) was used to construct the recombinant plasmids. BL21 Star ${ }^{\mathrm{TM}}$ (DE3) Chemically Competent E. coli (Life Technologies, Carlsbad, CA, USA) was used for transformation and protein expression. Expression vector constructions were done with pET101/D-TOPO $^{\circledR}$ (Life Technologies, Carlsbad, CA, USA) and pJexpress 401 (DNA2.0, Menlo Park, CA, USA).

\section{Construction of expression vectors pET101-HO}

The heme oxygenase gene (ho1) of Synechocystis PCC6803 was amplified by PCR of Biobrick gene part BBaI15008 (Registry of Standard Parts, The BioBricks Foundation, http://biobricks.org/) using forward primer 5'CACC ATGAGTGTC AACTTAGCTTC-3' and reverse primer 5'-CTAGCCTTCGGAGGTGGCGA-3' and cloned into pET101/D-TOPO ${ }^{\circledR}$ to generate plasmid vector pET101-HO1 (Figure 1A) with expression under T7lac promoter control according to instructions provided by Life Technologies (Carlsbad, CA) $\left(\right.$ TOPO $^{\circledR}$ Cloning Reaction Method). The hol gene sequence was verified by DNA sequencing. The vector pET101-HO1 was transformed into BL21 Star ${ }^{\mathrm{TM}}$ (DE3) Chemically Competent E. coli to give E. coli strain BL21(HO1).

\section{pJexpress401-mHO1}

The hol gene sequence was codon optimized for expression in E. coli using DNA2.0 Algorithms (DNA2.0, Inc., Menlo Park, CA, USA) (Figure 2). The coding sequence for hexahistidine was incorporated at the 5' end to provide a $6 \mathrm{X}$ His tag at the N-terminus of the synthesized protein. The E.coli codon optimized gene (mho1) was synthesized and inserted into plasmid vector pJexpress401 by DNA2.0 Inc. (Menlo Park, CA, USA). The resulting vector, pJexpress401-mHO1 (Figure 1B), was transformed into BL21 Star ${ }^{\mathrm{TM}}$ (DE3) Chemically Competent E. coli to give E. coli strain BL21(mHO1).

\section{Testing carbon sources for biliverdin production}

Several carbon sources at different concentrations and in combination were examined for capabilities to support 

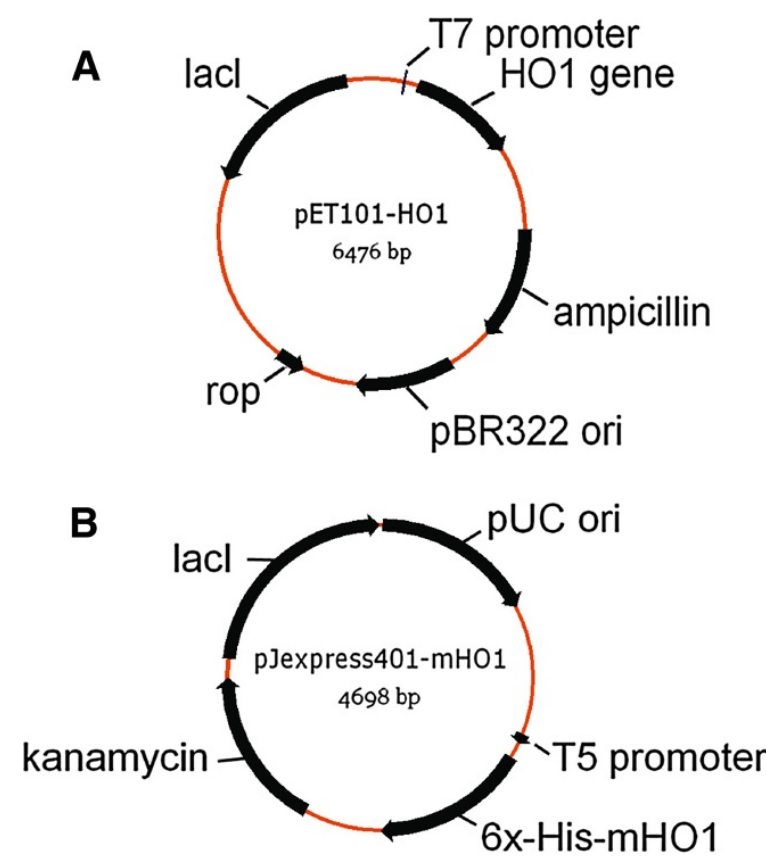

Figure 1 Gene maps of expression vectors pET101-HO1 (A) and pJexpress401-mHO1 (B). hol gene expression in (A) is controlled by T7lac promoter which consists of a strong bacteriophage T7 promoter and a downstream 25 bp lac operator in pET101. For mho1 expression (B), an "IP-free" T5 promoter sequence was used with the lac operator placed downstream of the T5 promoter in the vector pJexpress 401

growth and biliverdin synthesis by $E$. coli strains BL21 (HO1) and BL21(mHO1). Cultures were grown in $125 \mathrm{~mL}$ capacity Erlenmeyer flasks on a New Brunswick G76 rotary incubator shaker $\left(30^{\circ} \mathrm{C}, 200 \mathrm{rpm}\right)$ in $50 \mathrm{~mL}$ Luria-Bertani (LB) medium [42] with various single carbon sources that included sucrose $\left(1 \% \mathrm{wt} \mathrm{vol}^{-1}\right)$, mannitol $\left(0.1,1,2,5,10\right.$ and $20 \%$ wt vol$\left.^{-1}\right)$, sorbitol $(1,5,10$ and $\left.20 \% \mathrm{wt} \mathrm{vol}^{-1}\right)$, lactose $\left(1,2.5,5\right.$ and $\left.10 \% \mathrm{wt} \mathrm{vol}^{-1}\right)$, succinate $\left(2 \%\left(\mathrm{wt} \mathrm{vol}^{-1}\right)\right.$, malate $(2 \%)$ or combinations of carbon sources that included mannitol $\left(1 \%\right.$ wt vol ${ }^{-1)}+$ glucose $\left(1 \%\right.$ wt vol $\left.{ }^{-1}\right)$, sucrose $\left(1 \%\right.$ wt vol $\left.^{-1}\right)+$ glucose $\left(1 \%\right.$ wt vol $\left.^{-1}\right)$, mannitol $\left(1 \%\right.$ wt vol $\left.^{-1}\right)+\operatorname{sorbitol}(2.5 \%$ wt $\left.\mathrm{vol}^{-1}\right)$, or mannitol $\left(5 \% \mathrm{wt} \mathrm{vol}^{-1}\right)+\operatorname{sorbitol}\left(5 \% \mathrm{wt} \mathrm{vol}^{-1}\right)$. Ampicillin or kanamycin $\left(100 \mu \mathrm{g} \mathrm{mL}^{-1}\right)$ was used for selection, and isopropyl- $\beta$-thiogalactopyranoside (IPTG) $(0.5 \mathrm{mM})$ was added (at cell density with absorbance $(1 \mathrm{~cm})\left(\mathrm{A}_{600}\right)$ of $\left.\sim 0.5\right)$ as inducer except when lactose was the carbon source. Growth was monitored at $\mathrm{A}_{600}$ and the culture color was recorded when stationary phase growth was achieved (24 to $48 \mathrm{~h}$ ). Biliverdin levels were estimated by absorbance spectroscopy using a $\mathrm{mM}$ extinction coefficient of 25 at $650 \mathrm{~nm}(1 \mathrm{~cm}$ light path length) using a SpectraMax Plus384 Absorbance Microplate Reader (Molecular Devices, Sunnyvale, CA, USA).

\section{Biliverdin production using bioreactor batch cultures}

For bioreactor inocula, E. coli strains BL21(HO1) and BL21(mHO1) were grown in $50 \mathrm{~mL}$ of LB medium plus $100 \mu \mathrm{g} \mathrm{mL}^{-1}$ ampicillin or kanamycin, respectively, in $250 \mathrm{~mL}$ capacity Erlenmeyer flasks with rotary shaking (225 rpm) at $37^{\circ} \mathrm{C}$ to an $\mathrm{A}_{600}$ of 2 to 6 with $\mathrm{LB}$ medium as a blank control. Inoculum cultures $(80 \mathrm{~mL})$ were added to $2 \mathrm{~L}$ of modified New Brunswick Scientific (NBS) medium [43] with $2 \%\left(\mathrm{wt} \mathrm{vol}^{-1}\right)$ lactose in place of glucose or modified ZY medium [44] composed of per $\mathrm{L}$ : $2 \mathrm{~g}$ lactose, $2.2 \mathrm{~g}$ glucose, $16 \mathrm{~g}$ glycerol, $15 \mathrm{~g} \mathrm{~N}-\mathrm{Z}-\mathrm{Amine}^{\mathrm{TM}}$ A or $10 \mathrm{~g}$ Hy Express System II (Sheffield ${ }^{\mathrm{TM}}$ Bio-Science, Norwich, NY), $10 \mathrm{~g}$ yeast extract (FisherScientific), $1 \mathrm{~mL}$ $2 \mathrm{M} \mathrm{MgSO}_{4}, 50 \mathrm{~mL}$ of $20 \mathrm{X}$ NP solution $\left(66 \mathrm{~g}\left(\mathrm{NH}_{4}\right)_{2} \mathrm{SO}_{4}\right.$, $136 \mathrm{~g} \mathrm{KH}_{2} \mathrm{PO}_{4}, 142 \mathrm{~g} \mathrm{Na} \mathrm{Na}_{2} \mathrm{HPO}_{4}$ in $1 \mathrm{~L}$ twice-distilled $\mathrm{H}_{2} \mathrm{O}$ ), and $1 \mathrm{~mL} 1000 \mathrm{X}$ trace elements solution $(50 \mathrm{~mL}$ of $1 \% \mathrm{HCl}, 0.675 \mathrm{~g} \mathrm{FeCl}_{3}, 0.15 \mathrm{~g} \mathrm{CaCl}_{2}, 0.1 \mathrm{~g} \mathrm{MnCl}_{2}$, $0.015 \mathrm{~g} \mathrm{ZnSO}_{4}, 0.023 \mathrm{~g} \mathrm{CoCl}_{2}, 0.015 \mathrm{~g} \mathrm{CuCl}_{2}, 0.023 \mathrm{~g} \mathrm{NiCl}_{2}$, $0.025 \mathrm{~g} \mathrm{Na}_{2} \mathrm{MoO}_{4}, 0.007 \mathrm{~g} \mathrm{H}_{3} \mathrm{BO}_{3}$ in distilled water to a final volume of $250 \mathrm{~mL}$ ). Separately, 20X NP solution and $2 \mathrm{M} \mathrm{MgSO} 4$ were autoclaved and 1000X trace elements solution was filter-sterilized, and the solutions were added to complete the preparation of modified $\mathrm{ZY}$ growth medium. Batch culture growth was conducted in a New Brunswick Scientific (Endfield, CT, USA) Bioflo 310 Controller bioreactor using BioCommand software with a $5 \mathrm{~L}$ capacity vessel. A dissolved $\mathrm{O}_{2}$ level of $40 \%$ was cascade controlled and monitored by gassing with $\mathrm{O}_{2}(0-50 \%)$ and air $(0.75$ - 4 SLPM). No antifoam was used. For fed-batch experiments, a $200 \mathrm{~mL}$ solution of $10 \%\left(\mathrm{wt} \mathrm{vol}^{-1}\right.$ ) glycerol, $2 \%$ (wt vol ${ }^{-1}$ ) lactose, and with or without $5 \%$ (wt vol-1) peptone was continuously fed $\left(8 \mathrm{~mL} \mathrm{~h}^{-1} \mathrm{~L}^{-1}\right)$ during exponential growth beginning $4 \mathrm{~h}$ after inoculation. Cell culture absorbance $\left(\mathrm{A}_{600}\right)$ was approximately 10 at $4 \mathrm{~h}$ and 29 at $11 \mathrm{~h}$ after culture inoculation. Growth was terminated approximately $25 \mathrm{~h}$ after inoculation. Green material (containing biliverdin) accumulated in foam above the culture liquid surface and on the inner surfaces of the bioreactor vessel and in the foam over-flow material that was siphoned into a flask outside the vessel. The pigmented material was collected using methanol or distilled water as necessary and the $\mathrm{pH}$ of the final suspension was lowered to 4.3 or 4.5 , respectively, to promote biliverdin precipitation. The recovered material was centrifuged at $7477 \mathrm{xg}$ for 6 min, and the sedimented blue-green material was suspended in methanol. Non-sedimenting biliverdin in aqueous fractions was recovered by readjusting the $\mathrm{pH}$ to 4.3 followed by re-centrifugaton and suspension of the green pellet in methanol. The pooled methanolic solutions were placed on a rotating shaker $(225 \mathrm{rpm})$ at room temperature for $15 \mathrm{~min}$. The solution was centrifuged at $4500 \mathrm{xg}$ for $4 \mathrm{~min}$ to remove particles from solution. Fresh methanol was added to the pellet, and the 
extraction repeated. The extraction is further repeated with distilled methanol until the $A_{650}$ of a 1:10 dilution of the supernatant fluid is less than 0.5. The amounts of biliverdin recovered were quantitated by HPLC with comparisons to known amounts of authentic biliverdin IX $\alpha$ (Frontier Scientific, Inc., Logan, Utah).

Larger (100L) batch cultures of E. coli strain BL21 (HO1) were grown at $37^{\circ} \mathrm{C}$ with NBS medium containing $2 \%\left(\mathrm{wt} \mathrm{vol}^{-1}\right.$ ) lactose in a B. Braun UE-100D bioreactor (B. Braun Melsungen AG, Germany). Fed-batch mode was not used. E. coli strain BL21(HO1) inoculum cultures (4L) were grown overnight at $37^{\circ} \mathrm{C}$ in $\mathrm{LB}$ medium in Bioflo310 bioreactors. Inoculum cultures (4L) were added to $100 \mathrm{~L}$ growth medium and growth was terminated $24 \mathrm{~h}$ following inoculation. Biliverdin was collected, extracted and purified as described above for the $2 \mathrm{~L}$ bioreactor batch cultures.

\section{$\mathrm{HO}$ identification and activity \\ HO cell extraction}

Aliquots (48 to $400 \mathrm{~mL}$ ) of bioreactor batch cultures of E. coli strain BL21(mHO1) were collected at 2, 5, 10, 15 and $2 \mathrm{~h}$ after inoculation, centrifuged (4500xg, 5min), and the supernatant liquid discarded. The sedimented cell pellets were stored at $-20^{\circ} \mathrm{C}$. The cells were extracted, and proteins were recovered from Ni-NTA columns using the QIAexpress ${ }^{\circledR}$ Ni-NTA fast Start Kit (QIAGEN, Valencia, CA, USA) according to procedures described in the kit manual. 


\section{SDS-PAGE}

Twenty $\mu \mathrm{L}$ of each protein solution from Ni-NTA column purification were added to 20 $\mu$ Lof SDS-PAGE sample buffer (Bio-Rad, Hercules, CA, USA), heated for $10 \mathrm{~min}$ with boiling water, and centrifuged briefly. Supernatant liquid aliquots $(30 \mu \mathrm{L})$ were loaded into wells of Bio-Rad Criterion Precast Gels and electrophoresed in a Bio-Rad Criterion precast Gel System. The gel was stained using Bio-safe ${ }^{\mathrm{TM}}$ Coomassie G-250 (Bio-Rad, Hercules, CA, USA). Precision Plus Protein Prestained Standards (Bio-Rad Laboratories, Hercules, CA, USA) was used for estimation of protein molecular size.

\section{Identification}

Ni-NTA column purified protein samples were reduced and alkylated with iodoacetamide. The resulting peptides were concentrated on a ZipTip micropurification column and eluted onto an anchorchip target for analysis on a Bruker Autoflex III MALDI TOF/TOF instrument (performed by Alphalyse, Inc., Palo Alto, CA, 94306). The peptide mixture was analyzed in positive reflector mode for accurate peptide mass determination. MALDI MS/MS analyses were performed on 8 separate peptides for partial peptide sequencing. The MS and MS/MS spectra were combined and analyzed using Mascot software and NCBI protein databases.

\section{HO activity}

Harvested E. coli strains BL21(mHO1) and BL21 Star ${ }^{\mathrm{TM}}$ (DE3) cells were washed and suspended in assay buffer (50 mM Tris- $\mathrm{HCl}, \mathrm{pH} 7.7,10 \% \mathrm{wt} \mathrm{vol}^{-1}$ glycerol) and $1 \mathrm{mM}$ EDTA, and disrupted three times using a French press cell operated at $18,000 \mathrm{psi}$. The lysate was centrifuged at 15,000xg, and the supernatant fraction was used for $\mathrm{HO}$ activity assays similar to published procedures $[28,45]$. The enzyme reaction mixture $(500 \mu \mathrm{L})$ contained assay buffer, $40 \mu \mathrm{M}$ methemalbumin, $2.5 \mathrm{mM}$ Tiron, $20 \mu \mathrm{g} \mathrm{mL} \mathrm{m}^{-1}$ ferredoxin, 0.02 units of ferredoxin reductase (Sigma-Aldrich, St. Louis, USA), and cell lysate $(0.128 \mathrm{mg}$ protein). The reaction was initiated with the addition of $0.2 \mathrm{mg}$ of NADPH and the mixture was incubated at $37^{\circ} \mathrm{C}$ for $20 \mathrm{~min}$ in the dark. The mixture was then extracted and esterified [46] and biliverdin dimethyl ester was quantitated by HPLC using a Beckman C18 Ultrasphere column $(4.6 \mathrm{~mm} \times 15 \mathrm{~cm})$, elution with methanol, and absorbance measurement at $380 \mathrm{~nm}$.

\section{Biliverdin purification Purification}

Ammonium acetate $(0.1 \mathrm{M}, 1.5 \mathrm{~L})$ was mixed with biliverdin in buffered methanol $(60 \% 0.1 \mathrm{M}$ ammonium acetate $/ 40 \%$ methanol, $\mathrm{vol} \mathrm{vol}^{-1}, 1 \mathrm{~L}$ ) and the mixture was loaded onto a glass column $(4.0 \mathrm{~mm} \times 300 \mathrm{~mm})$ packed with $\mathrm{C} 18$ silica beads $(125 \AA$ pore, $55-105 \mu \mathrm{M}$ diameter, Waters, Manchester, UK). The column was preconditioned by sequential elution with $200 \mathrm{~mL}$ of methanol and $200 \mathrm{~mL}$ of buffered methanol. After loading the sample, the column was washed with $100 \mathrm{~mL}$ buffered methanol solution. Biliverdin was eluted with $30 \% 0.1 \mathrm{M}$ ammonium acetate $/ 70 \% \mathrm{MeOH}\left(\mathrm{vol} \mathrm{vol}^{-1)}\right.$ solution and collected as material in a green band. To $25 \mathrm{~mL}$ of eluted biliverdin material was gradually added $400 \mathrm{~mL}$ of $1 \mathrm{mM} \mathrm{HCl}$ with stirring. The solution was kept at $-20^{\circ} \mathrm{C}$ for $1 \mathrm{~h}$ and then centrifuged for $15 \mathrm{~min}$ at $11325 \mathrm{xg}$ at $4^{\circ} \mathrm{C}$. The supernatant fluid was removed, the biliverdin pellet was washed and suspended in $20 \mathrm{~mL}_{2} \mathrm{O}$ in a $50-\mathrm{mL}$ capacity plastic centrifuge tube and centrifuged for $15 \mathrm{~min}$ at $4500 \mathrm{xg}$ at $4{ }^{\circ} \mathrm{C}$. The supernatant fluid was discarded, the biliverdin pellet was frozen at $-80^{\circ} \mathrm{C}$ and then freeze-dried using a FreeZone Plus Freeze Dry System (Labconco, Kansas City, MO USA).

\section{Biliverdin characterization Absorbance spectra}

Absorbance spectra (300 and 800nm) were obtained using a SpectraMax Plus384 Absorbance Microplate Reader (Molecular Devices, Sunnyvale, CA, USA).

\section{HPLC analysis}

Biliverdin samples $(20 \mu \mathrm{L}$ were subjected to HPLC using a Symmetry ${ }^{\circledR}$ C18 column $(4.6 \mathrm{~mm} \times 75 \mathrm{~mm})$ and a gradient of solvent A: $99.9 \% \mathrm{H}_{2} 0,0.1 \%$ trifluoroacetic acid and solvent B: $99.9 \%$ methanol and $0.1 \%$ trifluoroacetic acid. The elution gradient program was: $100 \%$ solvent A, $1 \mathrm{~min} ; 0-60 \%$ solvent $\mathrm{B}, 1 \mathrm{~min} ; 60-100 \%$ solvent $\mathrm{B}, 8 \mathrm{~min}$, $0-100 \%$ solvent A, $1 \mathrm{~min} ; 100 \%$ solvent A, 4 min with a flow rate of $1 \mathrm{~mL} \mathrm{~min}{ }^{-1}$ using a Waters Alliance HPLC (Waters, Manchester, UK).

\section{Proton NMR analysis}

NMR data was collected on a JEOL Eclipse 400MhZ NMR (JEOL, Peabody, MA, USA). Biliverdin samples were dissolved in DMSO-d6 (Cambridge Isotope Labs, Andover, MA USA).

\section{LC-MS analysis}

Biliverdin samples were analyzed on a NanoACQUITY UPLC (Waters, Manchester, UK) and a Q-Tof Primer tandem mass spectrometer (Waters, Manchester, UK). Samples $(3 \mu \mathrm{L})$ were introduced into a Symmetry ${ }^{\circledR} \mathrm{C} 18$ trapping column $(180 \mu \mathrm{M} \times 20 \mathrm{~mm})$ with NanoACQUITY Sample Manager (Waters, Manchester, UK) washed with $99 \%$ solvent A and $1 \%$ solvent B for 3 min at $15 \mu \mathrm{L} \mathrm{min}^{-1}$. Solvent A was $99.9 \% \mathrm{H}_{2} 0,0.1 \%$ formic acid and solvent B was $99.9 \%$ acetonitrile and $0.1 \%$ formic acid. Chemicals were eluted from the trapping column over a 
BEH300 C4 column with a 40min gradient (1-4\% solvent B, 0.1min; 4-98\% solvent B, 19.9 min; $98-85 \%$ solvent B, $2 \mathrm{~min}$; $85 \%$ solvent $\mathrm{B}$, and $10 \mathrm{~min}, 85-1 \%$ solvent $\mathrm{B}, 8 \mathrm{~min}$ ) at a flow rate of $0.8 \mu \mathrm{L} \mathrm{min}{ }^{-1}$. MS scan time was $1.0 \mathrm{sec}$.

\section{NADPH biliverdin reductase activity}

The enzymatic conversion of biliverdin to bilirubin was measured using the Biliverdin Reductase Assay Kit (Sigma-Aldrich, St. Louis, MO, USA). One mg of biliverdin producd by strain E. coli strain BL21(mHO1) was dissolved in $2 \mathrm{~mL}$ methanol, and $0.2 \mathrm{~mL}$ was mixed with $1 \mathrm{~mL}$ of the kit assay buffer. The kit-supplied recombinant human biliverdin reductase A enzyme was suspended in $800 \mu \mathrm{L}$ water, and $160 \mu \mathrm{L}$ of the enzyme suspension was added to $480 \mu \mathrm{L}$ of assay buffer. Biliverdin-containing kit assay buffer $(50 \mu \mathrm{L})$, biliverdin reductase solution $(200 \mu \mathrm{L})$, and NADPH solution $\left(0.24 \mathrm{mg} \mathrm{mL}^{-1} \mathrm{NADPH}\right.$ in assay buffer, $750 \mu \mathrm{L}$ ) were combined and the absorbance spectrum between 300-800nm was measured at $0,15,30,45,60,90$, 145, 240 and 360min using a SpectraMax Plus384 Absorbance Microplate Reader (Molecular Devices, Sunnyvale, CA, USA).

\section{Results and discussion}

\section{Effect of carbon source on biliverdin production}

Several potential carbon sources, alone and in combination, were examined for their abilities to support biliverdin production by $E$. coli strains BL21(HO1) and BL21(mHO1) growing in LB medium (Table 1). Lactose at 2 and $2.5 \%\left(w \mathrm{vol}^{-1}\right.$ ) alone or in combination with Dglucose yielded green cultures containing 2 to $4 \mathrm{mg} \mathrm{L}^{-1}$ biliverdin without IPTG addition. E. coli strain BL21 (HO1) cultures grown with D-mannitol (alone or in combination with glucose or sorbitol) also yielded green cultures whereas other carbon compounds and combinations (Table 1) yielded brown or yellow-green and pale green cultures containing $<0.2$ and $<2 \mathrm{mg} \mathrm{L}^{-1}$ biliverdin, respectively. Similarly, E. coli strain BL21(mHO1) produced enhanced amounts of biliverdin with lactose alone or in combination with D-glucose. These results show that certain carbohydrates and particularly lactose (2 to $\left.2.5 \% \mathrm{wt} \mathrm{vol}^{-1}\right)$, alone or in combination with D-glucose, and D-mannitol (2 to $5 \%$ wt vol ${ }^{-1}$ ) support higher levels of biliverdin production by $E$. coli strains BL21(HO1) and BL21(mHO1) growing in LB medium as compared to other carbon sources. With lactose, the addition of IPTG was not required for enhanced biliverdin production offering a practical and economic advantage for large-scale, commercial production of biliverdin.

\section{Bioreactor batch culture production of biliverdin}

Based on observations that lactose enhanced biliverdin production, modified ZY medium containing $2 \% \mathrm{wt} \mathrm{vol}^{-1}$ lactose was used to grow E. coli strains BL21(HO1) and
Table 1 Biliverdin production by E. coli (HO1) and E. coli (mHO-1) growing in LB medium supplemented with various carbon sources

\begin{tabular}{|c|c|c|c|c|}
\hline E.coli Strain & Carbon Source & Conc. $\%$ & IPTG $^{a}$ & Pigment $^{\mathrm{b}}$ \\
\hline \multirow[t]{25}{*}{ BL21(HO1) } & D-glucose & 1 & + & pale green \\
\hline & & 2 & + & pale green \\
\hline & & 5 & + & yellow green \\
\hline & sucrose & 1 & + & brown \\
\hline & D-mannitol & 1 & + & pale green \\
\hline & & 2 & + & pale green \\
\hline & & 5 & + & green \\
\hline & D-sorbitol & 1 & + & yellow green \\
\hline & & 5 & + & yellow green \\
\hline & & 10 & + & yellow green \\
\hline & lactose & 1 & - & pale green \\
\hline & & 2.5 & - & green \\
\hline & & 5 & - & yellow green \\
\hline & & 10 & - & yellow green \\
\hline & D-mannitol, D-glucose & 1,1 & + & pale green \\
\hline & sucrose, D-glucose & 1,1 & + & pale green \\
\hline & D-mannitol, D-sorbitol & $2.5,2.5$ & + & green \\
\hline & D-mannitol, D-sorbitol & 2,5 & + & green \\
\hline & D-mannitol, D-sorbitol & 5,5 & + & green \\
\hline & lactose, D-glucose & 2,2 & - & green \\
\hline & succinate & 5 & + & pale green \\
\hline & malate & 5 & + & pale green \\
\hline & citrate & 5 & + & pale green \\
\hline & L- glutamate & 5 & + & pale green \\
\hline & L- glutamate & 5 & + & yellow green \\
\hline \multirow[t]{4}{*}{ BL21 (mHO1) } & D-glucose & 1 & + & green \\
\hline & D-mannitol & 5 & + & green \\
\hline & lactose & 2.5 & - & green \\
\hline & lactose, D-glucose & 2,2 & - & green \\
\hline
\end{tabular}

asopropyl- $\beta$-thiogalactoside (IPTG), $0.5 \mathrm{mM}$ added (+), or not added (-). b Biliverdin concentrations were 2 to $4 \mathrm{mg} \mathrm{L}^{-1}$ (green), $<2$ to $>0.2 \mathrm{mg} \mathrm{L}^{-1}$ (pale green) and $<0.2 \mathrm{mg} \mathrm{L}^{-1}$ (yellow green and brown).

BL21(mHO1) in 2 L volumes in a New Brunswick Scientific Bioflo 310 Controller bioreactor. Consistent biliverdin production was achieved with $40 \%$ dissolved $\mathrm{O}_{2}$, agitation between 280 and $500 \mathrm{rpm}$, and continuous feeding of lactose $\left(2 \% \mathrm{wt} \mathrm{vol}^{-1}\right)$ and glycerol (10\% wt vol $\left.{ }^{-1}\right)$ in fed-batch mode initiated $4 \mathrm{~h}$ after culture inoculation (exponential growth phase). Biliverdin was visible as and collected in green material that accumulated in the foam above the culture liquid surface (Figure 3). Biliverdin was identified and quantitated by HPLC analyses of the collected material. E. coli strains BL21(HO1) and E. coli BL21(mHO1) produced between 2.5 and $5 \mathrm{mg}(\mathrm{n}=3$, 


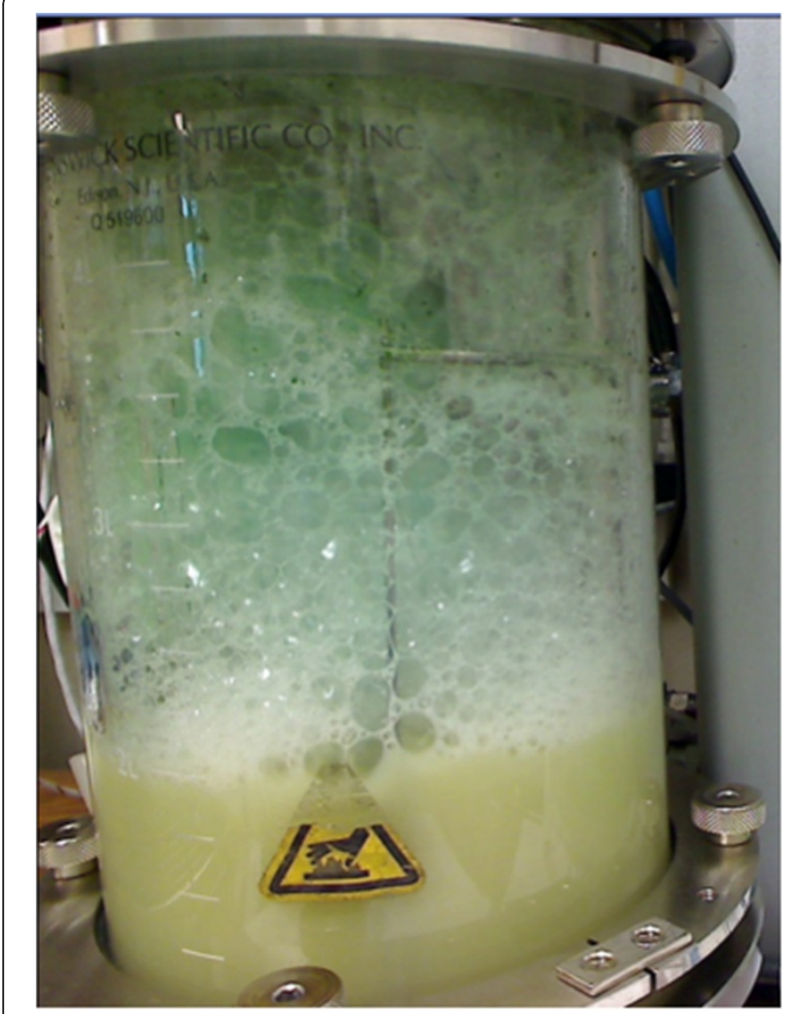

Figure 3 Biliverdin production from E. coli strain BL21 (mHO1) growing in modified ZY medium in a New Brunswick Bioflo 310 bioreactor. Biliverdin is subsequently extracted from the greencolored material that accumulates above the culture surface. average $3.3 \mathrm{mg})$ and between 5.3 to $7.5 \mathrm{mg}(\mathrm{n}=9$, average $6.4 \mathrm{mg}$ ) of biliverdin, respectively, per $\mathrm{L}$ of culture. Therefore, E. coli strain BL21(mHO1) produced nearly twice the amount of biliverdin than E.coli strain BL21(HO1) in the bioreactor cultures growing in modified ZY medium in fed-batch mode with lactose and glycerol. In contrast, the two strains produced approximately the same amounts of biliverdin when grown in LB medium with lactose $\left(2.5 \% \mathrm{wt} \mathrm{vol}^{-1}\right)$ in small shaker flasks (Table 1$)$. When peptone was included in the fed-batch medium (together with lactose and glycerol), E. coli strain BL21 (mHO1) bioreactor cultures produced between18.4 to $25.3 \mathrm{mg} \mathrm{L}^{-1}\left(\mathrm{n}=11\right.$, average of $\left.23.8 \mathrm{mg} \mathrm{L}^{-1}\right)$ of biliverdin. E.coli strain BL21(HO1) produced between 3 and $3.9 \mathrm{mg}$ $\mathrm{L}^{-1}\left(\mathrm{n}=9\right.$, average of $\left.3.3 \mathrm{mgL}^{-1}\right)$ in modified NBS medium in batch mode.

Biliverdin production was also achieved in a $100 \mathrm{~L}$ bioreactor (Braun UE-100D) batch mode cultures of E. coli strain BL21(HO1) grown in NBS medium containing 2\% $\left(\mathrm{wt} \mathrm{vol}^{-1}\right.$ ) lactose. Biliverdin yields ranging between 200 to $311 \mathrm{mg}(\mathrm{n}=5$, average 212$)$ were achieved. This rate of production was similar to that achieved by $E$. coli strain BL21(HO1) in the 2L bioreactor (Bioflo 310) batch mode cultures (average rate: $3.3 \mathrm{mg} \mathrm{L}^{-1}$ ) indicating that biliverdin production by $E$. coli strain BL21(HO1) is scalable to larger volumes and quantities.

\section{HO expression and activity}

When grown in $2 \mathrm{~L}$ bioreactor cultures, E. coli strain BL21(mHO1) cells contained Ni-NTA recoverable proteins with molecular size $\sim 29 \mathrm{Kd}$ and detectable initially between 2 to $5 \mathrm{~h}$ after inoculation and then until growth was terminated (25h) (Figure 4). The proteins were equivalent in size to ho1 of Synechocystis PCC6803 with a $6 \mathrm{x}$-His tag (i.e. $28.7 \mathrm{Kd}$ ) and the gel excised protein showed sequence similarity to the cyanobacterial ho1 (31\% sequence coverage, Mascot protein score $=146$ ). Extracts of E. coli strain BL21(mHO1) cells harvested at $25 \mathrm{~h}$ of bioreactor growth had $\mathrm{HO}$ activities of $80 \mathrm{pmol}$ $\mathrm{hr}^{-1} \mathrm{mg}$ protein $^{-1}$ whereas extracts from $E$. coli strain BL21 Star ${ }^{\mathrm{TM}}$ (DE3) cells showed no or barely detectable activities $\left(<5 \mathrm{pmol} \mathrm{hr}^{-1} \mathrm{mg}\right.$ protein $\left.{ }^{-1}\right)$. These results confirmed that E. coli strain BL21(mHO1) synthesized an $\mathrm{HO}$ enzyme when grown under conditions that allowed accumulation of green pigment determined to be biliverdin (see below).

\section{Identification of biliverdin IXa}

The identity of the biliverdin extracted from E. coli strain BL21(mHO1) cultures as biliverdin IX $\alpha$ was indicated by comparisons to authentic biliverdin IX $\alpha$ using

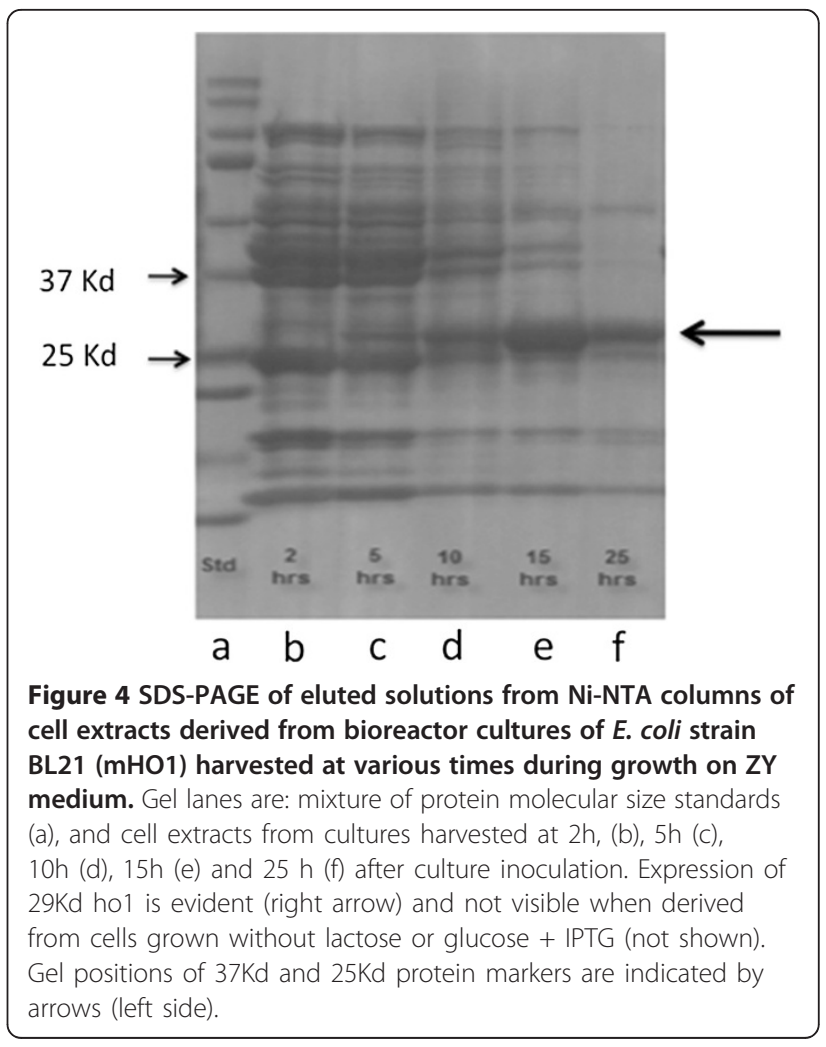




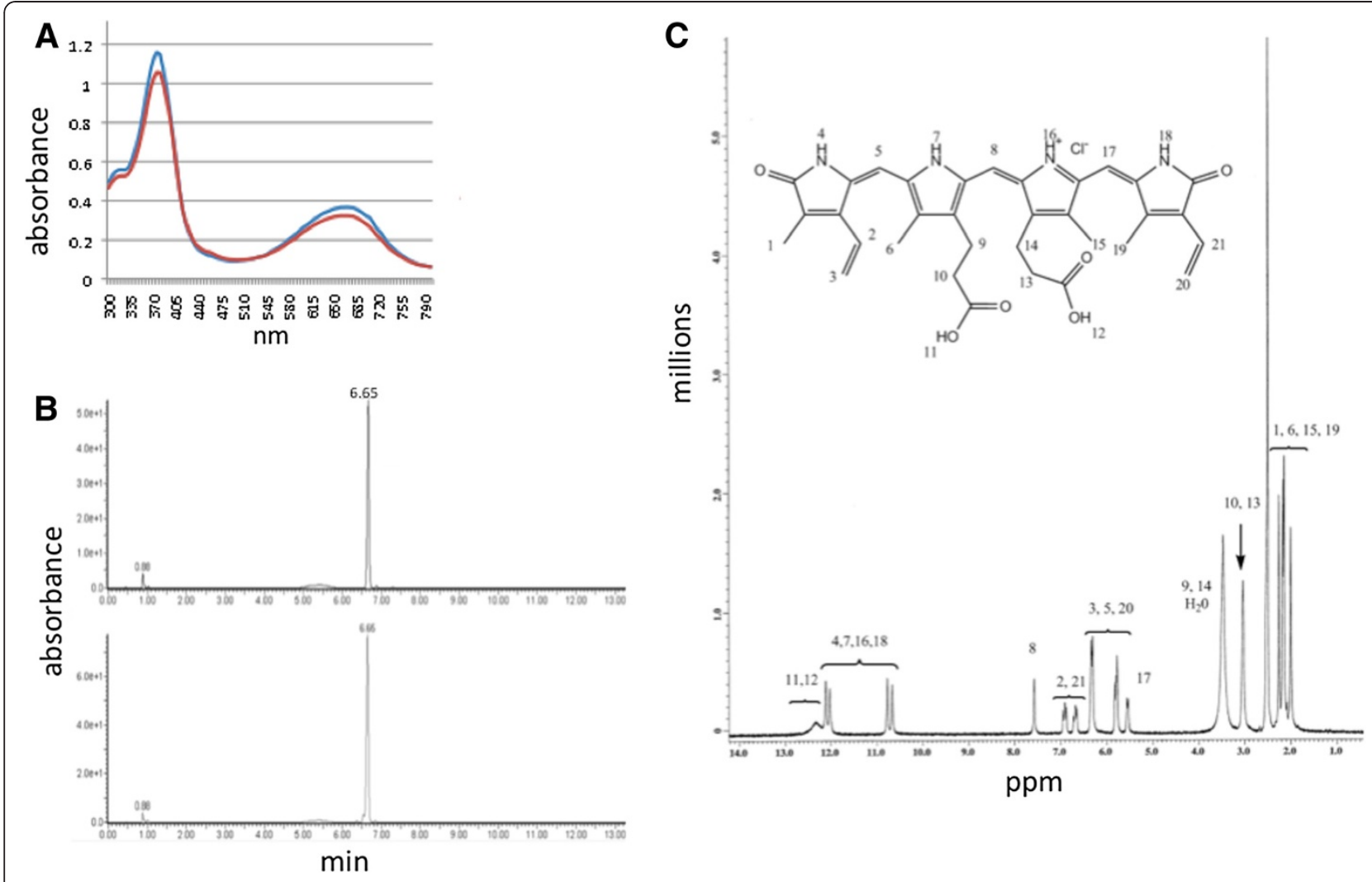

Figure 5 Spectral and chromatographic analyses of biliverdin produced by bioreactor cultures of $E$. coli BL21 (mHO1). (A) Absorbance spectra of biliverdin produced by E. coli BL21 ( $\mathrm{mHO1}$ ) (red) and commercial biliverdin IXa derived from an animal source (b/ue). (B) HPLC chromatograms of biliverdin produced by E. coli BL21 ( $\mathrm{HHO1}$ ) (top) and commercial biliverdin IXa derived from an animal source (bottom). (C) One dimensional proton NMR (400 Mhz) spectrum of E. coli BL21 (mHO1)-produced biliverdin in DMSO-d6. ${ }^{1} \mathrm{H}$ NMR (400 MHz, DMSO) signal assignments are: $12.32(\mathrm{~s} ; 2 \mathrm{H}) ; 12.1(\mathrm{~s} ; 1 \mathrm{H}) ; 12.01(\mathrm{~s} ; 1 \mathrm{H}) ; 10.78(\mathrm{~s} ; 1 \mathrm{H}) ; 10.67(\mathrm{~s} ; 1 \mathrm{H}) ; 7.58(\mathrm{~s} ; 1 \mathrm{H}) ; 6.91(\mathrm{t}, \mathrm{J}=15.6 \mathrm{~Hz} ; 1 \mathrm{H}) ; 6.69(\mathrm{t}, \mathrm{J}=15.2 \mathrm{~Hz} ; 1 \mathrm{H}) ; 6.32$ (d, J=12.2 Hz; 3H); $5.82(\mathrm{~d}, \mathrm{~J}=10.8 \mathrm{~Hz} ; 1 \mathrm{H}) ; 5.56(\mathrm{~d}, \mathrm{~J}=11.2 \mathrm{~Hz} ; 1 \mathrm{H}) ; 5.78(\mathrm{~s} ; 1 \mathrm{H}) ; 3.05(\mathrm{~m} ; 4 \mathrm{H}) ; 3.43(\mathrm{~m} ; 4 \mathrm{H}) ; 2.18(\mathrm{~s} ; 3 \mathrm{H}) ; 2.27(\mathrm{~s} ; 3 \mathrm{H}) ; 2.15(\mathrm{~s} ; 3 \mathrm{H}) ; 2.01$ $(s ; 3 H)$. The spectrum is similar to biliverdin IXa derived from animal sources [36].

absorbance spectroscopy, HPLC, proton NMR spectroscopy (Figure 5) and mass spectroscopy (mass 582.2). The degree of purity was $>98 \%$ based on HPLC profiles (biliverdin IX $\alpha$ retention time of $6.6 \mathrm{~min}$, Figure 5B).

\section{E. coli produced biliverdin as substrate for biliverdin reductase $A$}

Purified biliverdin produced by E. coli BL21(mHO1) was reduced to bilirubin IX $\alpha$ by recombinant human biliverdin reductase A and NADPH (Figure 6). Since human biliverdin reductase A specifically uses biliverdin IX $\alpha$ as substrate $[1,35]$, this result confirms the identity of the E. coli $\mathrm{BL} 21(\mathrm{mHO} 1)$ produced biliverdin as the IX $\alpha$ isomer. It also suggests that the produced biliverdin has therapeutic potential because of its substrate interaction with the human enzyme and its facile conversion to bilirubin IX $\alpha$.

\section{Conclusions}

Methods for the scalable production of biliverdin by $E$. coli cultures were developed. Production is enhanced

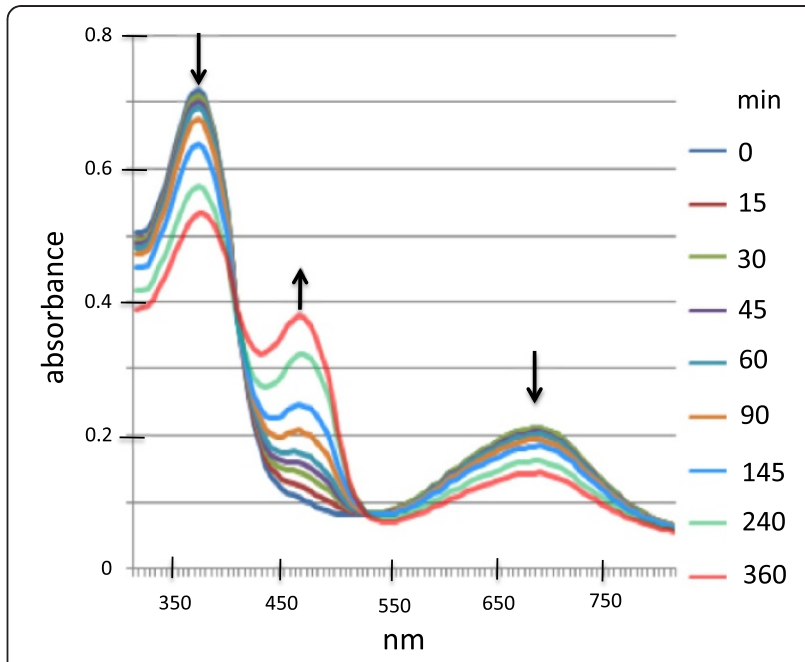

Figure 6 Absorbance spectra at various times during bilirubin formation from E. coli BL21 (mHO1)-produced biliverdin catalyzed by human recombinant biliverdin reductase $A$.

NADPH-dependent reduction was monitored spectrophotometrically for $6 \mathrm{~h}$. The arrows indicate the direction of absorbance change over time during the reaction. 
with the use of an altered version of a cyanobacterial ho1 gene that is sequence-optimized for E. coli expression. The produced biliverdin is solely the physiologically relevant IX $\alpha$ isomer and is easily obtained at a high degree of purity (>98\%). Its purity and ability to serve as substrate for human NADPH biliverdin reductase A suggest its potential as a clinically useful therapeutic for inflammatory diseases and conditions. When commercially produced for therapeutic applications, the biliverdin IX $\alpha$ preparations will undoubtedly require screening for and elimination of endotoxin contaminants that are a consequence and limitation of industrial scale production by E. coli cultures.

\section{Abbreviations \\ HO: Heme oxygenase; ROS: Reactive oxygen species; NAPDH: Reduced nicotinamide dinucleotide phosphate; IPTG: Isopropyl- \\ $\beta$-thiogalactopyranoside; HPLC: High performance liquid chromatography; UPLC: Ultra high performance liquid chromatography; Ni-NTA: Nickel- nitriloacetic acid; NMR: Nuclear magnetic resonance.}

\section{Competing interests}

A utility patent application to the U.S. Patent and Trademark Office (No. 12/ 939,880 , filed November 4, 2010) on topics related to the contents of this manuscript is pending. DC, JDB, YK and JYT are supported by Utah State University that has applied for the patent.

\section{Authors' contributions}

DC designed and conducted experiments related to gene cloning, protein expression, biliverdin purification and characterization and wrote parts of the manuscript. JDB and YK designed and conducted microbiological and bioreactor experiments. JB conducted chemical analysis and purification protocols. JYT designed experiments, coordinated the research, and wrote the manuscript. All authors read and approved the final manuscript.

\section{Acknowledgements}

The research was supported by the Utah Science,Technology and Research (USTAR) Initiative, State of Utah, and the Synthetic Bioproducts Center, Utah State University, Logan, Utah USA. The technical assistance of M. Chambers, S. Bedingfeld, and M. Sims are acknowledged. D. Cefalo (Frontier Scientific, Logan Utah) performed NMR analyses.

\section{Author details}

'Synthetic Bioproducts Center, 620 North 600 East, Utah State University, North Logan, Utah 84341, USA. ²Department of Biology, 5305 Old Main Hill, Utah State University, Logan, Utah 84322, USA. ${ }^{3}$ Frontier Scientific, Inc, 195 South 700 West, Logan, Utah 84323, USA.

Received: 21 June 2012 Accepted: 4 October 2012 Published: 23 November 2012

\section{References}

1. McDonagh AF: Turning green to gold. Nat Struct Bio/ 2001, 8(3):198-200.

2. Sedlak TW, Snyder SH: Bilirubin benefits: cellular protection by a biliverdin reductase antioxidant cycle. Pediatrics 2004, 113(6):1776-1782.

3. Soares MP, Bach FH: Heme oxygenase-1: from biology to therapeutic potential. Trends Mol Med 2009, 15(2):50-58.

4. Baranano DE, Rao M, Ferris CD, Snyder SH: Biliverdin reductase: a major physiologic cytoprotectant. Proc Natl Acad Sci USA 2002, 99(25):16093-16098.

5. Maghzal GJ, Leck MC, Collinson E, Li C, Stocker R: Limited role for the bilirubin-biliverdin redox amplification cycle in the cellular antioxidant protection by biliverdin reductase. J Biol Chem 2009, 284(43):29251-29259.

6. McDonagh AF: The biliverdin-bilirubin antioxidant cycle of cellular protection: missing a wheel? Free Rad Biol Med 2010, 49(5):814-820.

7. Sedlak TW, Snyder SH: Cycling the wagons for biliverdin reductase. J Biol Chem 2009, 284(46):le11. author reply le12.
8. Fujii M, Inoguchi T, Sasaki S, Maeda Y, Zheng J, Kobayashi K, Takayanagi R: Bilirubin and biliverdin protect rodents against diabetic nephropathy by downregulating NAD(P)H oxidase. Kidney Int 2010, 78(9):905-919.

9. Nakao A, Murase N, Ho C, Toyokawa H, Billiar TR, Kanno S: Biliverdin administration prevents the formation of intimal hyperplasia induced by vascular injury. Circulation 2005, 112(4):587-591.

10. Nakao A, Otterbein LE, Overhaus M, Sarady JK, Tsung A, Kimizuka K, Nalesnik MA, Kaizu T, Uchiyama T, Liu F, et al: Biliverdin protects the functional integrity of a transplanted syngeneic small bowel. Gastroenterol 2004, 127(2):595-606.

11. Overhaus M, Moore BA, Barbato JE, Behrendt FF, Doering JG, Bauer AJ: Biliverdin protects against polymicrobial sepsis by modulating inflammatory mediators. Gastrointest Liver Physiol 2006, 290(4):G695-703.

12. Yamashita K, McDaid J, Ollinger R, Tsui T-Y, Berberat PO, Usheva A, Csizmadia EVA, Smith RN, Soares MP, Bach FH: Biliverdin, a natural product of heme catabolism, induces tolerance to cardiac allografts. FASEB J 2004, 18(6):765-767.

13. Bellner $L$, Wolstein J, Patil KA, Dunn MW, Laniado-Schwartzman M: Biliverdin rescues the $\mathrm{HO}-2$ null mouse phenotype of unresolved chronic inflammation following corneal epithelial injury. Invest Ophthalmol Vis Sci 2011, 52(6):3246-3253.

14. Wegiel B, Baty CJ, Gallo D, Csizmadia E, Scott JR, Akhavan A, Chin BY, Kaczmarek E, Alam J, Bach FH, et al: Cell surface biliverdin reductase mediates biliverdin-induced anti-inflammatory effects via phosphatidylinositol 3kinase and Akt. J Biol Chem 2009, 284(32):21369-21378.

15. Wegiel B, Gallo D, Csizmadia E, Roger T, Kaczmarek E, Harris C, Zuckerbraun BS, Otterbein LE: Biliverdin inhibits Toll-like receptor-4 (TLR4) expression through nitric oxide-dependent nuclear translocation of biliverdin reductase. Proc Natl Acad Sci 2011, 108(46):18849-18854.

16. Florczyk UM, Jozkowicz A, Dulak J: Biliverdin reductase: new features of an old enzyme and its potential therapeutic significance. Pharmacol Rep 2008, 60(1):38-48.

17. Wegiel B, Otterbein L: Go green: the anti-inflammatory effects of biliverdin reductase. Front Pharmacol 2012, 3(47):1-8.

18. Wang H, Ferran C, Attanasio C, Calise F, Otterbein LE: Induction of protective genes leads to islet survival and function. J Transplant 2011, 2011:141898.

19. Fondevila C, Katori M, Lassman C, Carmody I, Busuttil RW, Bach FH, KupiecWeglinski JW: Biliverdin protects rat livers from ischemia/reperfusion injury. Transplant Proc 2003, 35(5):1798-1799.

20. Ollinger R, Bilban M, Erat A, Froio A, McDaid J, Tyagi S, Csizmadia E, GracaSouza AV, Liloia A, Soares MP, et al: Bilirubin: A natural inhibitor of vascular smooth muscle cell proliferation. Circulation 2005, 112(7):1030-1039.

21. Sarady-Andrews JK, Liu F, Gallo D, Nakao A, Overhaus M, Jñllinger R, Choi AM, Otterbein LE: Biliverdin administration protects against endotoxininduced acute lung injury in rats. Amer J Physiol - Lung Cell Mol Physiol 2005, 289(6):L1131-L1137.

22. Zhu Z, Wilson AT, Luxon BA, Brown KE, Mathahs MM, Bandyopadhyay S, McCaffrey AP, Schmidt WN: Biliverdin inhibits hepatitis $C$ virus nonstructural 3/4A protease activity: mechanism for the antiviral effects of heme oxygenase? Hepatol 2010, 52(6):1897-1905.

23. McPhee F, Caldera PS, Bemis GW, McDonagh AF, Kuntz ID, Craik CS: Bile pigments as HIV-1 protease inhibitors and their effects on HIV-1 viral maturation and infectivity in vitro. Biochem J 1996, 320(Pt 2):681-686.

24. Nakagami T, Taji S, Takahashi M, Yamanishi K: Antiviral activity of a bile pigment, biliverdin, against human herpesvirus 6 (HHV-6) in vitro. Microbiol Immunol 1992, 36(4):381-390.

25. Ikeda N, Inoguchi $T$, Sonoda N, Fujii M, Takei R, Hirata E, Yokomizo H, Zheng J, Maeda Y, Kobayashi K, et al: Biliverdin protects against the deterioration of glucose tolerance in $\mathrm{db} / \mathrm{db}$ mice. Diabetologia 2011, 54(8):2183-2191.

26. Beale SI, Cornejo J: Biosynthesis of phycocyanobilin from exogenous labeled biliverdin in Cyanidium caldarium. Arch Biochem Biophys 1983, 227(1):279-286.

27. Elich TD, McDonagh AF, Palma LA, Lagarias JC: Phytochrome chromophore biosynthesis. Treatment of tetrapyrrole-deficient Avena explants with natural and non-natural bilatrienes leads to formation of spectrally active holoproteins. J Bio/ Chem 1989, 264(1):183-189.

28. Muramoto T, Tsurui N, Terry MJ, Yokota A, Kohchi T: Expression and biochemical properties of a ferredoxin-dependent heme oxygenase required for phytochrome chromophore synthesis. Plant Physiol 2002, 130(4):1958-1966. 
29. Rhie GE, Beale SI: Phycobilin biosynthesis: reductant requirements and product identification for heme oxygenase from Cyanidium caldarium. Arch Biochem Biophys 1995, 320(1):182-194.

30. Wilks A, Schmitt MP: Expression and characterization of a heme oxygenase (Hmu O) from Corynebacterium diphtheriae. Iron acquisition requires oxidative cleavage of the heme macrocycle. J Biol Chem 1998, 273(2):837-841.

31. Schluchter WM, Glazer AN: Characterization of cyanobacterial biliverdin reductase. Conversion of biliverdin to bilirubin is important for normal phycobiliprotein biosynthesis. J Biol Chem 1997, 272(21):13562-13569.

32. Giraud E, Fardoux J, Fourrier N, Hannibal L, Genty B, Bouyer P, Dreyfus B, Vermeglio A: Bacteriophytochrome controls photosystem synthesis in anoxygenic bacteria. Nat 2002, 417(6885):202-205.

33. Kaneko T, Sato S, Kotani H, Tanaka A, Asamizu E, Nakamura Y, Miyajima N, Hirosawa M, Sugiura M, Sasamoto S, Kimura T, Hosouchi T, Matsuno A Muraki A, Nakazaki N, Naruo K, Okumura S, Shimpo S, Takeuchi C, Wada T, Watanabe A, Yamada M, Yasuda M, Tabata S: Sequence analysis of the genome of the unicellular cyanobacterium Synechocystis sp. strain PCC6803. II. Sequence determination of the entire genome and assignment of potential protein-coding regions. DNA Res 1996, 3(3):109-136.

34. Richaud C, Zabulon G: The heme oxygenase gene (pbsA) in the red alga Rhodella violacea is discontinuous and transcriptionally activated during iron limitation. Proc Natl Acad Sci USA 1997, 94(21):11736-11741.

35. McDonagh AF, Palma LA: Preparation and properties of crystalline biliverdin IX alpha. Simple methods for preparing isomerically homogeneous biliverdin and [14C[biliverdin by using 2,3-dichloro-5,6dicyanobenzoquinone. Biochem J 1980, 189(2):193-208.

36. McDonagh AF: Biliverdin, immune-mediated liver injury, and the Gigo effect. Hepatol 2005, 41(3):680-681. author reply 681

37. Ishikawa K, Sato M, Yoshida T: Expression of rat heme oxygenase in Escherichia coli as a catalytically active, full-length form that binds to bacterial membranes. Eur J Biochem 1991, 202(1):161-165.

38. Wilks A, Ortiz de Montellano PR: Rat liver heme oxygenase. High level expression of a truncated soluble form and nature of the mesohydroxylating species. J Biol Chem 1993, 268(30):22357-22362.

39. Cornejo J, Willows RD, Beale SI: Phytobilin biosynthesis: cloning and expression of a gene encoding soluble ferredoxin-dependent heme oxygenase from Synechocystis sp. PCC 6803. Plant J 1998, 15(1):99-107.

40. Pendrak ML, Roberts DD: Methods for the production of biliverdin, US 2005/ 0209305 A1. USA: US Patent Application Publication; 2005.

41. Ding $Z K, X U$ YQ: Purification and characterization of biliverdin IXa from Atlantic salmon (Salmo salar) bile. Biochem (Moscow) 2002, 67:927-932.

42. Sambrook J, Fritsch EF, Maniatis T: Molecular cloning: a laboratory manual. Cold Spring Harbor, New York: Cold Spring Harbor Laboratory; 1989.

43. Vyas R: Basics of benchtop fermentor operation for growth of E. coli, BioTechniques Protocol Guide.; 2008. 2008:29. Print.

44. Studier FW: Protein production by auto-induction in high density shaking cultures. Protein Expr Purif 2005, 41(1):207-234.

45. Tenhunen R, Marver HS, Schmid R: The enzymatic conversion of heme to bilirubin by microsomal heme oxygenase. Proc Natl Acad Sci USA 1968, 61(2):748-755.

46. O'Carra P, Colleran E: Separation and identification of biliverdin isomers and isomer analysis of phycobilins and bilirubin. J Chromatogr 1970, 50(3):458-468

\section{Submit your next manuscript to BioMed Central and take full advantage of:}

- Convenient online submission

- Thorough peer review

- No space constraints or color figure charges

- Immediate publication on acceptance

- Inclusion in PubMed, CAS, Scopus and Google Scholar

- Research which is freely available for redistribution

Submit your manuscript at www.biomedcentral.com/submit
C Biomed Central 